\title{
Assessment of Columbia River Sediment Toxicity to White Sturgeon: Concentrations of Metals in Sediment, Pore water and Overlying Water
}

\author{
David W Vardy ${ }^{1^{*}}$, Jon A Doering ${ }^{1}$, Robert Santore ${ }^{2}$, Adam Ryan ${ }^{2}$, John P Giesy ${ }^{1,3,4,5}$ and Markus Hecker ${ }^{1,6,7}$ \\ ${ }^{1}$ Toxicology Centre, University of Saskatchewan, Saskatoon, SK, Canada \\ ${ }^{2}$ HDR HydroQual, Syracuse, NY, USA \\ ${ }^{3}$ Department of Biomedical Veterinary Sciences, University of Saskatchewan, Saskatoon, Saskatchewan, Canada \\ ${ }^{4}$ Zoology Department and Center for Integrative Toxicology, Michigan State University, East Lansing, Michigan, USA \\ ${ }^{5}$ Department of Biology and Chemistry and State Key Laboratory in Marine Pollution, City University of Hong Kong, Kowloon, Hong Kong, SAR, China \\ ${ }^{6}$ Cardno ENTRIX Inc, Saskatoon, SK, Canada \\ ${ }^{7}$ School of the Environment \& Sustainability, University of Saskatchewan, Saskatoon, SK, Canada
}

\begin{abstract}
Concentrations of copper, lead and zinc in sediments downstream of a metallurgical facility on the the Upper Columbia River (UCR) were significantly greater than those in regional reference locations. Sturgeons inhabit benthic habitats and there is concern that they might be at greater risk of exposure. A laboratory based, flow-through, experimental exposure system was used to characterize toxicity of metals in the different matrices associated with sediments collected from the UCR, and to assess risk to early life stages of white sturgeon (Acipenser transmontanus) under chronic bioassay conditions. Bioavailability and concentrations of metals in pore water, overlying water, and at the sediment-water interface were characterized. Several sampling methods including peepers, diffusive gradients in thin films (DGTs), and active sampling/suction techniques were employed. Results indicated that concentrations of metals in site sediments were significantly greater in comparison to upstream reference sediments. Of the four primary metals of concern, concentrations of copper, primarily in pore water, were significantly greater in exposure chambers containing site sediments compared to reference sediments. In addition, the different sampling techniques resulted in varying estimates of concentration depending on matrix, analyte, and method, and the present study highlights challenges in assessing the true risk of exposure. The analytical data reported herein is utilized in a parallel article to characterize risk and compare predictions to the bioassay results.
\end{abstract}

Keywords: Sturgeon; Columbia River; Metal toxicity; Pore Water Sampling; Risk Assessment

\section{Introduction}

Alteration of habitat, including pollution, is hypothesized as a major contributing factor to the global decline of populations of sturgeons [1-6]. Given their epi-benthic nature, sturgeon are potentially at risk of exposure to contaminants associated with sediments. In the Upper Columbia River (UCR), between Grand Coulee Dam in the USA and Hugh L. Keenleyside Dam in southern British Columbia, Canada, resides a population of fewer than 2500 white sturgeon (Acipenser transmontanus) that have been experiencing poor recruitment for over forty years $[4,7,8]$. Although specific reasons for their decline are not fully understood, pollution has been hypothesized as a potential contributing factor to the observed recruitment failure [8]. Specifically, there are concerns that contaminated sediments in the UCR may be bioavailable to sturgeon and that early life stages, including the early hiding stage where fry are in proximity to sediments, may be at risk.

The UCR is subject to multiple sources of pollution, including discharges from pulp and paper mills, wastewater treatment plants, and diverse mining and smelting operations [8]. In particular, a metallurgical facility in Trail, BC, Canada, historically released slag into the river, and historically and presently releases liquid effluents. Slag is a partially vitreous by-product of the metal refining process and there are concerns about the leaching of metals into water. Elevated concentrations of trace-elements, such as copper $(\mathrm{Cu})$, lead $(\mathrm{Pb})$, cadmium $(\mathrm{Cd})$, and zinc $(\mathrm{Zn})$, relative to reference sites, have been found in sediments downstream of the metallurgical facility [9-12]. Sediments are sinks for pollutants and can contain elevated concentrations of metals, which can be released back into the water column following remobilization [13,14]. Therefore, in addition to exposure to pollutants in the water column, sturgeon might be exposed to contaminants associated with sediments or contaminants released into the sediment-water interface.

In order to assess the risk posed by exposure to metals bound in sediments of demersal fishes, such as sturgeon, bioavailability and concentrations of metals in pore water, overlying water, and at the sediment-water interface, need to be characterized. exposure to metals bound in sediments to demersal fishes, such as sturgeon, bioavailability and concentrations of metals in pore water, overlying water, and at the sediment-water interface, need to be characterized. Total concentrations of metals in sediments are poor indicators of potential toxicity and risk because a significant proportion of metal might be sequestered and biologically unavailable [15]. The bioavailable fraction of a metal is largely dependent on modifying factors of the environment, both abiotic and biotic, that influence the amount of a metal that can interact with biological processes in an organism, and thus, result in toxicity [16]. Redox potential and $\mathrm{pH}$ can greatly affect the chemistry of a sediment-bound metal, governing its distribution between the solid and dissolved phases, and in turn its movement between the various matrices, with dissolved metals in pore water considered to be the most

*Corresponding author: David W Vardy, 44 Campus Dr, Saskatoon, SK, S7N 5B3 Canada, Tel: (306) 966-4557; E-mail: d.vardy@usask.ca or markus.hecker@usask.ca

Received January 03, 2015; Accepted January 20, 2015; Published January 24, 2015

Citation: Vardy DW, Doering JA, Santore R, Ryan A, Giesy JP et al. (2015) Assessment of Columbia River Sediment Toxicity to White Sturgeon: Concentrations of Metals in Sediment, Pore water and Overlying Water. J Environ Anal Toxicol 5: 263. doi:10.4172/2161-0525.1000263

Copyright: ( 2015 Vardy DW, et al. This is an open-access article distributed under the terms of the Creative Commons Attribution License, which permits unrestricted use, distribution, and reproduction in any medium, provided the original author and source are credited. 
bioavailable $[15,16]$. To assess the bioavailability and toxicity of metals associated with sediments various techniques have been employed, several of which include chemical analysis of whole digested sediment samples, or active or passive measurements of concentrations of metals in pore water using centrifugation or sampling devices such as peepers or diffusive gradients in thin films (DGTs).

Previous studies have investigated releases of elements from contaminated sediments in the Columbia River by use of several methods, such as quantification of metals in pore water (interstitial water), overlying water, and supernatants of aggressively tumbled slurries $[17,18]$. From these studies Paulson and Cox [18] concluded that under certain conditions releases of elements from sediment could result in concentrations of metals in various matrices that might be toxic to aquatic organisms. However, the Paulson and Cox [18] study employed techniques to simulate the potential release of metals from sediments under laboratory conditions that are unlikely to be directly applicable to conditions found in the above-mentioned region of concern of the UCR. Therefore, the purpose of the present study was to assess toxicity of chemicals of potential concern (COPC) associated with sediments to early life stage white sturgeon in the UCR by use of a controlled, laboratory, fluvial, exposure that simulated water quality characteristics found within the UCR in the vicinity downstream of Trail, BC, Canada. The present study was conducted under the oversight of the US EPA (www.ucr-rifs.com), and data obtained from this work will be used to supplement information in a baseline ecological risk assessment (BERA) and as part of a remedial investigation and feasibility study (RI/FS).

In order to accurately assess toxicity of UCR sediments to white sturgeon, a laboratory-based experimental design was needed that captured potential exposure routes of early life stages of white sturgeon to COPC, especially metals in the river, while assessing bioavailability by allowing quantification of chemical parameters in several matrices. To assess bioavailability of metals in UCR sediments and overlying waters, the present study employed a variety of sampling techniques. Peepers [19], DGTs [20], and active sampling/suction techniques were employed as a multiple lines of evidence approach to investigate concentrations of metals and chemical parameters in various matrices and to compare results of the various methods. Typically, analysis of pore water is achieved through either active or passive sampling, such as centrifuged and filtered core samples or use of membranes and dialysis chambers (peepers). Because disturbances of sediments during sampling of pore waters have been found to alter chemistries of sediments and affect bioavailability [21], in the present study peepers were employed to minimize disruption of sediment during sampling and extraction. In addition, peepers enable direct comparisons of concentrations of metals in pore water and overlying water [22], which is where early life stages of white sturgeon are likely to occur.

As a secondary measure and to compare concentrations of metals in pore water and at the sediment-water interface, DGT's were employed. DGTs utilize an ion-exchange resin and an ion-permeable gel membrane to quantitatively measure concentrations of metals in situ [20], and are a relatively non-intrusive method of sampling. Lastly, active sampling methods through direct collection of overlying water, sediment-water interface water, and pore water, by use of suction techniques with syringes, pipettes, and sediment-embedded air stones, were employed. These sampling techniques allowed for a greater volume of water to be collected from the relevant locations, which facilitated a larger suite of chemical analyses.

To identify specific data needs in addressing the aforementioned concerns and to establish decision rules for the collection of data, the EPA data quality objective (DQO) process [23] was used for this study. Specific DQOs addressed included survival and growth of white sturgeon reared on sediments from the UCR relative to reference sediments. The present article reports concentrations of metals to which early life stages of white sturgeon could be exposed and bioavailability of metals associated with sediments from the UCR. The responses of white sturgeon are presented separately [24].

\section{Methods}

\section{Site selection and collection of sediments}

Locations in the UCR from which sediments were collected were in areas known to encompass confirmed white sturgeon spawningand/or nursing-grounds [25,26], as well as to represent a range of exposure conditions $[11,12]$. Sampling focused on the reach of the UCR between Kettle Falls (river mile [RM] 703) to the U.S.-Canada border (RM 745), and was intended to represent a gradient of COPC concentrations in sediments associated with granulated slag $[11,12]$. Specifically, the primary COPCs were postulated to include $\mathrm{Cd}, \mathrm{Cu}, \mathrm{Pb}$, and $\mathrm{Zn}[11,12]$. Areas from which samples of sediments were collected included Deadman's Eddy (DME; RM 737), Northport (NP; RM 735), Little Dalles (LD; RM 729), China Bend (CB; RM 723), Upper Marcus Flats (UMF; RM 706), and Lower Marcus Flats (LMF; RM 704; see Supplemental Materials Map 1). Each sampling area contained three distinct sampling locations. Research and ground disturbance permits where obtained prior to sediment sampling and sampling activities were conducted under supervision of a Cultural Resources Working Group, with archaeological monitoring of ground-disturbing activities by a qualified archaeologist meeting the U.S. Secretary of Interior's Professional Qualification Standards. Reference sediments were collected in three areas located upstream of Trail, British Columbia, Canada. These included Birchbank Eddy (BBE; RM 764), Genelle (GE; RM 766), and Lower Arrow Lakes (LALL; RM 788; Supplemental Materials Map 2). In addition to site-specific sediments and reference sediments, artificial substratum sediment (Aquarium Substratum Item No. 12648, Rolf C. Hagen Inc., Baie d'Urfe, QC, Canada) was also used as a negative control (CTRL), as evaluated and selected through method development work (see study design section in methods and Supplemental Material).

Surface sediments, defined as the upper 10 to $15 \mathrm{~cm}$ (4 to 6 in.) of the sediment column, were collected using a custom-built stainless steel power VanVeen grab sampler that was specifically designed to operate in hard bottom substrata. Depending on sampling success, as much as ten 20-L (5-gal) polyethylene buckets per sampling location (30 buckets per sampling area) were collected to attain the target sediment volume of approximately $200-\mathrm{L}(\sim 50 \mathrm{gal})$ per location. Immediately after collection, sediments were transferred into $20-\mathrm{L}$ decontaminated polyethylene buckets, sealed, and transported in a refrigerated truck $\left(4^{\circ} \mathrm{C}\right)$ to the University of Saskatchewan (UofS), Saskatoon, Saskatchewan, Canada where they were held at $4^{\circ} \mathrm{C}$ until initiation of experiments.

Prior to use, composites of each type of sediment were made by thoroughly homogenizing individual samples within an area for site sediments collected from the potentially affected areas of the UCR, reference sediments, and control sediments. This was achieved by use of a Teflon-lined, cement mixer retrofitted with a high density polyethylene drum and stainless steel paddles, as deemed an appropriate and effective method of mixing through method development work (Supplemental Material) 


\section{Study design}

Prior to initiation of the definitive study, extensive method development work was conducted in order to evaluate and inform critical design components and considerations of specifically designed flow-through, fluvial simulation system for use in sediment toxicity tests with early life stage white sturgeon at the UofS ATRF. Specifically, an experimental exposure system was needed to allow for adjustment of flow velocity, water replacement time, and recirculation frequency, and provide versatility in sampling techniques while maintaining a practical and reproducible fluvial exposure. A full description of method development work, results, and final test design is provided in Supplemental Material.

Exposure chambers were continuous flow-through systems designed and operated at a rate of flow of approximately $20 \mathrm{~L} / \mathrm{min}$, with an illumination cycle of 16-light:8-dark (16:8) hrs., and target water temperature of $16 \pm 1^{\circ} \mathrm{C}$. Water was both renewed and re-circulated within each system. Flow-through conditions were set such that, on average, one complete water replacement in each exposure system occurred every $6 \mathrm{~h}$. Test water used during the study had a target water hardness of 65 to $70 \mathrm{mg} / \mathrm{L}$ as $\mathrm{CaCO}_{3}$ to simulate conditions found in the UCR, and consisted of a 1:1 mixture of de-chlorinated City of Saskatoon water and ATRF reverse osmosis water. The overall study design elements were in accordance with standard American Society for Testing Materials (ASTM) guidelines for testing early life stages of fish [27], with minor modifications for white sturgeon.

Homogenized sediments were evenly layered at the bottom of dedicated continuous flow-through exposure chambers at a thickness of approximately 2 inches. Replicate exposure chambers were established based on available sediment volume, with up to a maximum of six replicates per sample location. In addition to exposure chambers containing site sediments, reference sediments, or control sediment, a second negative control (water-only $\left[\mathrm{H}_{2} \mathrm{O}\right]$ control) was also established and monitored throughout the duration of the study. Six replicates were established for sediments collected from UMF01, LD-01, and LALL, four replicates from LMF-02 and GE, and two replicates from NP-03. In addition, three replicates from substrata collected above the water line from the gravel bar at Deadman's Eddy (hereafter referred to as "DE") were also included, as there was difficulty in collecting sufficient volumes of site sediments (see results section).

In order to create a pseudo-hyporheic zone, large pebbles (Aquarium Substratum Item No. 12422, Rolf C. Hagen Inc., Baie d'Urfe, QC, Canada) were systematically placed in each exposure chamber at approximately 4 stones per $100 \mathrm{~cm}^{2}$ to fulfill early life stage white sturgeon habitat requirements (Supplemental Material).

\section{Collection of water and pore water}

Concentrations of metals were quantified in overlying water, sediment-water interface water, and pore water to characterize exposure through the various possible aqueous exposure routes. Of the 42 exposure chambers, 11 were designated as chemistry-only (Supplemental Material), in which passive sampling devices, such as peepers and DGT probes, were installed and used to obtain additional water quality information within the top $\pm 1 \mathrm{~cm}$ of the sediment-water interface. Given that both DGT probes and peepers require a distinct period of equilibration ( 2 and 7 days, respectively), and necessitate disturbing the sediment during deployment and retrieval, dedicated chemistry-only exposure chambers were used for these measurements. These exposure chambers were seeded with the same number of white sturgeon and treated in the same manner as the regular exposure chambers except for the incorporation of the additional analytical devices. Exposure chambers designated as chemistry-only were to ensure that potential stress, if any, resulting from perturbations in deploying and retrieving DGT probes and peepers were not erroneously considered when interpreting effects on white sturgeon.

Direct sampling of pore water and overlying water: During placement of sediments/substrata into test chambers, up to eight ceramic air-stones (RENA Micro Bubbler 6-in. ceramic air-stones, Mars Inc., Hackettstown, NJ, USA) were distributed along the length of each exposure chamber for non-intrusive collection of pore water at a depth of approximately $2.5 \mathrm{~cm}$ ( $1 \mathrm{in}$.) below the sediment surface (Supplemental Material). Each air-stone was connected to a $15-\mathrm{ml}$ syringe through a port in the side of the exposure chamber that would allow for extraction of pore water (Supplemental Material). Samples of water were also collected at the sediment-water interface and overlying water via suction by use of high density polyethylene (HDPE) pipettes and syringes, respectively. For the purpose of the present study, sediment-water interface water is defined as that water located within the boundary between sediment and the overlying water column, within $1 \mathrm{~cm}$ above the sediment surface, within respective exposure chambers. Samples of overlying water within exposure chambers were collected within the top $15 \mathrm{~cm}$ (6 in.) of the water column.

Passive sampling of pore water and sediment-water interface: Additional samples of pore water and sediment-water interface were collected by use of alternative passive sampling devices, specifically peepers [19] and DGT probes [20]. Peepers were obtained from the Liber laboratory, UofS, Saskatoon, SK, Canada, and DGT probes were obtained from DGT Research Ltd, Lancaster, UK. These samples were collected to provide comparative data at the sediment-water interface, and to collect pore water data within the top $1 \mathrm{~cm}(0.4 \mathrm{in}$.) of the sediment profile. Samples collected with peepers and DGT probes were collected at the beginning (Day 8), middle (Day 27), and end (Day 57) of the study, following a 2-day (DGT) and a 7-day (peeper) equilibration period. Preparation, placement and retrieval of peepers followed methods described by Doig and Liber [19]. In short, peepers were placed in the sediment so that the top chamber sampled the sediment-water interface and the bottom chamber sampled pore water at approximately a depth of $1 \mathrm{~cm}$. Each chamber was filled with Nano pure water and a $0.45-\mu \mathrm{m}$ polyethersulfone filter membrane (Whatman, Sigma-Aldrich, Oakville, ON, Canada) was used to separate the chambers from the media. Following the 7-day equilibration period, peepers were removed from designated chemistry-only exposure chambers and rinsed with deionized water to remove any residual particles from the $0.45-\mu \mathrm{m}$ membrane surface. Using a plastic tip equipped pipette, peeper membranes were pierced and their contents immediately transferred into pre-cleaned HDPE or polypropylene vials (as provided by Columbia Analytical Services [CAS], Kelso, WA, USA), preserved, and transported to CAS for chemical analysis. Given the limited sample volumes associated with peepers, chemical analyses focused on dissolved metals.

Preparation, placement, and retrieval of DGTs followed methods described by Zhang [28], with the exception that probes were placed horizontally within the sediments as opposed to vertically, as deemed an acceptable method of sampling water at the sediment-water interface and pore water $1 \mathrm{~cm}$ below the sediment surface (personal communication with Zhang H.). Following the 2-day period of equilibration, DGT probes were carefully extracted from designated "chemistry-only" exposure chambers and rinsed with deionized water, 
removing any residual particles from the gel surface. Upon removal and rinsing, DGT probes were sliced along the sediment-surface water line using a Teflon coated blade. Respective top and bottom gel portions were further sliced into three equal stripes, transferred into dedicated 15-mL high-density polypropylene centrifuge tubes, preserved with $5-\mathrm{mL}$ of $1-\mathrm{M} \mathrm{HNO}_{3}$, and transported to CAS for chemical analysis.

\section{Sampling of sediments}

Following homogenization and prior to placement in the exposure chambers at the initiation of the study, sub-samples of sediment were collected for each sampled site and submitted to CAS for chemical analyses (see chemical analysis and water quality section in methods). Furthermore, at the end of the study, samples of sediments were also collected from each exposure chamber and submitted for further analytical testing (see chemical analysis and water quality section in methods). In addition, confirmatory analytical testing of reference and control sediments was also completed prior to study initiation.

\section{Chemical analysis and water quality}

As required by the design (see Supplemental Materials), temperature, $\mathrm{pH}$, dissolved oxygen (DO), and conductivity were monitored daily using appropriate YSI electrodes (YSI Inc., Yellow Springs, OH, USA), while alkalinity, inorganic nitrogen, such as ammonia and nitrate, and hardness were monitored weekly using LaMotte Company colorimetric and titration test kits (Chestertown, MD, USA). In addition, pore water (at $2.5 \mathrm{~cm}$ below the sediment surface), sediment-water interface, and overlying water samples were collected weekly and submitted to CAS for chemical analyses.

All water samples were analyzed for target analyte list (TAL) metals, major cations/anions, alkalinity, hardness, and organic carbon (dissolved and total fractions). TAL metals (dissolved and total fractions) included: aluminum ( $\mathrm{Al})$, antimony $(\mathrm{Sb})$, arsenic (As), barium $(\mathrm{Ba})$, beryllium $(\mathrm{Be}), \mathrm{Cd}$, chromium $(\mathrm{Cr})$, cobalt $(\mathrm{Co}), \mathrm{Cu}$, iron $(\mathrm{Fe}), \mathrm{Pb}$, manganese $(\mathrm{Mn})$, mercury $(\mathrm{Hg})$, molybdenum (Mo), nickel $(\mathrm{Ni})$, selenium $(\mathrm{Se})$, silver $(\mathrm{Ag})$, thallium $(\mathrm{Tl})$, vanadium $(\mathrm{V})$, and $\mathrm{Zn}$. Major cations/anions as defined for this study include: calcium $(\mathrm{Ca})$, magnesium $(\mathrm{Mg})$, potassium $(\mathrm{K})$, sodium $(\mathrm{Na})$, sulfate $\left(\mathrm{SO}_{4}\right)$, chloride $(\mathrm{Cl})$, and fluoride $(\mathrm{F})$. All water samples, including pore water, sedimentwater interface, and overlying water, were extracted using acid-cleaned and nanopure water rinsed HDPE syringes. With the exception of dissolved fractions, extracted samples were directly discharged into pre-preserved sampling containers (see Supplemental Materials for list of preservatives), and transported at $4^{\circ} \mathrm{C}$ to CAS for chemical analysis. Samples in which analyses required the dissolved fraction were filtered through $0.45-\mu \mathrm{m}$ polyethersulfone filters (Whatman, Sigma-Aldrich, Oakville, ON, Canada) before being transferred into pre-preserved sampling containers. A summary of analytical methods and associated detection limits employed by CAS for water samples in the present study is provided in Supplemental Materials.

Total concentrations of TAL metals, Acid Volatile Sulfide (AVS) and simultaneously extracted metals (SEM), total organic carbon (TOC), polychlorinated biphenyls (PCBs), organochlorine pesticides, polycyclic aromatic hydrocarbons (PAHs), $\mathrm{pH}$, and grain size were determined for all samples of sediment. Organochlorine pesticides included Dichloro Diphenyl Trichloroethane DDT), dichlorodiphenyldichloroethylene (DDE), and dichlorodiphenyldichloroethane (DDD). A summary of analytical methods and associated detection limits for sediment/ substratum samples is provided in Supplemental Materials.

\section{Validation assessment- overall data quality}

Environmental Standards Inc. (ESI; Valley Forge, PA, USA) performed an independent quality assurance and data validation review of the results produced by CAS. The review was performed in accordance with requirements specified by US EPA guidance documents [29-32]. Data were examined to determine usability of the analytical results and compliance relative to requirements specified above and the analytical methods. In addition, deliverables were evaluated for completeness and accuracy. Most analytical data were useable ( $>88 \%)$, with qualifications presented in data validation reports and summarized in Supplemental Materials. Only useable data were included herein. There were instances where analytes were considered "not-detected" because they were detected at concentrations equivalent to that in the associated field blanks. For these samples, concentrations were reported as the Limit Of Quantification [29-32]. In cases where measured values were $10 \mathrm{x} \geq$ the associated blank, measured values were reported directly without correction. An EPA Quality Assurance/ Quality Control (QA/QC) chemist reviewed the draft data and data validation reports, and EPA approved the data for public use.

During routine cleaning operations of exposure chambers UMF-D (Day 22) and CTRL-D (Day 23), a significant number of sturgeon fry were lost. Given that these events occurred well beyond the 48$\mathrm{hr}$ permissible re-seeding window, these exposure chambers could no longer be used for biological measurements, such as survival and growth. Nevertheless, in an attempt to salvage information from these exposure chambers, they were converted into and designated as chemistry-only replicates (see collection of water and pore water section in methods).

\section{Statistics}

Analytical data were categorized based upon sample type, including overlying water, sediment-water interface, and pore water, treatment type, such as sediment source at LALL, GE, DE, NP, LD, UMF, or LMF, tank replicate, and measurement type, including acid-extractable and dissolved metal. These categories allowed for explicit and systematic processing of data to quantify and evaluate a wide-range of exposure conditions throughout the duration of the study.

Concentrations were summarized on the basis of sources of sediments, replicate tank, and depth within exposure chambers. In addition, techniques for collecting samples of water were factored into the analysis. As noted in sections 2.3, as many as three distinct sampling techniques, such as suction, peepers, and DGT probes, were employed to characterize sediment-water interface and pore water samples. Data for each of these sampling techniques were used to quantify concentrations of various analytes within exposure chambers.

In some instances, concentrations of metals were less than the Limit of Quantification (LOQ) and thus, resulted in non-detectable concentrations. Given the relatively large number of non-detectable concentrations observed during the present study, summary statistics and statistical comparisons and correlations were determined using maximum likelihood estimate (MLE) procedures. MLE procedures consider the presence of non-detectable concentrations when estimating parameters such as the mean, median, and variance for a given dataset. Procedures such as MLE provide better estimates of statistics for censored data, for samples for which the concentration is less than the limit of detection than simple "blind" calculations that treat BDLs as detected measurements or 'fabricating' values with the use of substitution methods, such as one-half the value of the detection 
limit [33]. A detailed description and reasoning for use of the MLE procedure employed in the present study is provided in Supplemental Materials. Conformation of distributions of data to approximate the normal probability function and equal variances was assessed by use of box and probability plots. If parametric assumptions were met, statistical comparisons of concentrations of metals within the different matrices of exposure chambers containing site sediments versus reference sediments were calculated using analysis of variance (ANOVA) and Dunnett's equivalents following MLE procedures. If parametric assumptions were violated, a Wilcoxon Score Test was performed following MLE procedures. When appropriate, statistical significance was adjusted with a Bonferroni correction factor. In addition, to investigate relationships between sampling techniques within a matrix, and concentrations of metal in sediment to concentrations in pore water and overlying water, linear regression and correlation coefficients were used following MLE procedures. Linear regression analyses were performed on measurements obtained from active sampling techniques, such as acid-extractable metals in whole sediments and sampling of matrices through suction. All data analysis procedures were conducted with $\mathrm{R}$ version 2.9.1 [34].

\section{Results and Discussion}

\section{Characterization of sediments}

Despite the relatively large sampling area, the presence of coarsegrained substrata, such as gravels, cobbles, and boulders, and an armored riverbed made collecting sufficiently large volumes of sediment difficult in some locations. Sediments were collected from NP, LD, UMF, LMF, LALL and GE, with volumes at LD, NP, and LMF being less than the targeted $600 \mathrm{~L}$ (Supplemental Material). Insufficient volumes of sediment were retrieved from $\mathrm{CB}, \mathrm{DE}$, and BBE. Given the difficulty in collecting sufficient volumes of site sediments, substrata collected above the water line from the gravel bar at DE were incorporated into this study, as directed by EPA.

With locations where sediment was collected targeted in areas north of RM-703 that contain white sturgeon spawning- and/or nursing-grounds, it is reasonable that predominant sediment grain sizes collected and evaluated for the present study were sand-sized particles, having diameters ranging from very coarse $(1<2.0 \mathrm{~mm})$ to very fine $(62.5<125 \mu \mathrm{m})$ sands. The mean grain size distribution of site sediments was approximately $0.5 \%$ gravels, $97.3 \%$ sands, and $1.9 \%$ silts/clays (Supplemental Material). Reference sediments were slightly coarser with a mean grain size distribution of $20.9 \%$ gravels, $76.5 \%$ sands, and $1.4 \%$ silts/clays.

Since the primary focus of this study was to assess toxicity of early life stages of white sturgeon, under laboratory controlled conditions, to a gradient of COPC associated with sediments, with a primary focus on those COPC commonly associated with granulated slag, the target metals were $\mathrm{Cd}, \mathrm{Cu}, \mathrm{Pb}$ and $\mathrm{Zn}$. The analyses presented here focus on these four metals. However, data for all COPC in whole sediment are presented in Supplemental Materials. Sediment concentrations of Cd, $\mathrm{Cu}, \mathrm{Pb}$ and $\mathrm{Zn}$ were significantly greater $(\mathrm{p}<0.01)$ in all site sediment samples than in reference sediments (Supplemental Materials).

Concentrations of metals spanned the spectrum of concentrations observed to date within the site, and often exceeded the $90^{\text {th }}$ centile of previously reported data (Figure 1) [11,12]. Similarly, concentrations within reference sediments were lesser, often less than the $10^{\text {th }}$ centile of site sediments. Based on these results, sediments evaluated for this study appear representative and consistent of the range of concentrations observed with site sediments.

\section{Characterization of water samples}

Major cation/anion water quality conditions: Concentrations for major cations/anions, including calcium $\left(\mathrm{Ca}^{++}\right)$, potassium $\left(\mathrm{K}^{+}\right)$, sodium $\left(\mathrm{Na}^{+}\right)$, and sulfate $\left(\mathrm{SO}_{4}^{-2}\right)$ within overlying water and pore water (at $2.5 \mathrm{~cm}$ depth) were consistent between treatments and for the duration of the study (Supplemental Material). Unlike major cations/ anions, concentrations of DOC were more variable among treatments (e.g., LALL and DE) and greater within pore waters than overlying waters. A significant number of measured concentrations of DOC were qualified as estimated due to field duplicate imprecisions. As a result, summary statistics for reported DOC concentrations were corrected for these imprecisions by factoring in any reported blank contamination (see application of biotic ligand model section in methods in [24])

Concentrations of major cations/anions in water collected from the sediment-water interface measured by use of suction (pipette) and peeper techniques were comparable, with concentrations calculated by use of DGT probes being different (Supplemental Material). Given that DGT probes used in the present study were specifically designed and deployed to measure the flux of the four primary metals of interest $(\mathrm{Cu}, \mathrm{Cd}, \mathrm{Pb}$, and $\mathrm{Zn})$, calculated concentrations of major cations for the DGTs was likely due to saturation of the resin in the DGTs. Because diffusion coefficients are comparable in magnitude, fluxes of the cations comprising the hardness are on the order of 2,000 to 20,000 times greater than typical trace metal fluxes, the potential existed for the resin to become saturated over a time scale of hours rather than days $[35,36]$. Data for pore water quality at the $1 \mathrm{~cm}$ depth was limited because samples were collected via peepers and DGT probes only.

\section{Dissolved concentrations of target metals}

Copper: There were significant differences $(p<0.01)$ in concentrations of dissolved $\mathrm{Cu}$ between exposure chambers containing site sediments versus reference sediments (Figure 2; Supplemental Materials). Dissolved concentrations of $\mathrm{Cu}$ in negative controls $\left(\mathrm{H}_{2} \mathrm{O}\right.$ and CTRL) and reference sediment (LALL and GE) exposure chambers were consistently lesser for the duration of the study with estimated median concentrations $\leq 1 \mu \mathrm{g} / \mathrm{L}$ for all matrices, including overlying water, sediment-water interface, and pore water. In comparison, concentrations of $\mathrm{Cu}$ measured in samples containing UCR site sediments were significantly greater $(\mathrm{p} \leq 0.001)$ in all matrices compared to those of reference sediments, with the exception of a few measurements from passive sampling devices in DE and LMF sediment, and active sampling at the sediment-water interface in NP sediments (Supplemental Materials). The greatest concentrations of $\mathrm{Cu}$ were observed in pore water collected at a depth of $2.5 \mathrm{~cm}$. In exposure chambers containing DE, $\mathrm{LD}$, and UMF sediments median concentrations of 30,20 , and $10 \mu \mathrm{g} \mathrm{Cu} / \mathrm{L}$, respectively were measured in pore waters (Figure 2). In contrast, estimated median concentrations of $\mathrm{Cu}$ in pore water at $2.5 \mathrm{~cm}$ for exposure chambers containing sediments from NP and LMF approached 3 and $1 \mu \mathrm{g} / \mathrm{L}$, respectively. Concentrations of $\mathrm{Cu}$ in pore water collected at a depth of $1 \mathrm{~cm}$ were lesser than those samples collected at $2.5 \mathrm{~cm}$ for exposure chambers containing DE, LD, and UMF sediments, with estimated median values $<4 \mu \mathrm{g} / \mathrm{L}$. Concentrations of $\mathrm{Cu}$ were comparable between pore water depths for exposure chambers containing NP and LMF sediments. In overlying water and at the sediment-water interface, estimated median concentrations of $\mathrm{Cu}$ in samples from exposure chambers containing site sediments $(0.8-2 \mu \mathrm{g} / \mathrm{L})$ were equal to or slightly greater than the estimated median concentrations of $\mathrm{Cu}$ in control and reference sediments $(<1 \mu \mathrm{g} / \mathrm{L})$. 

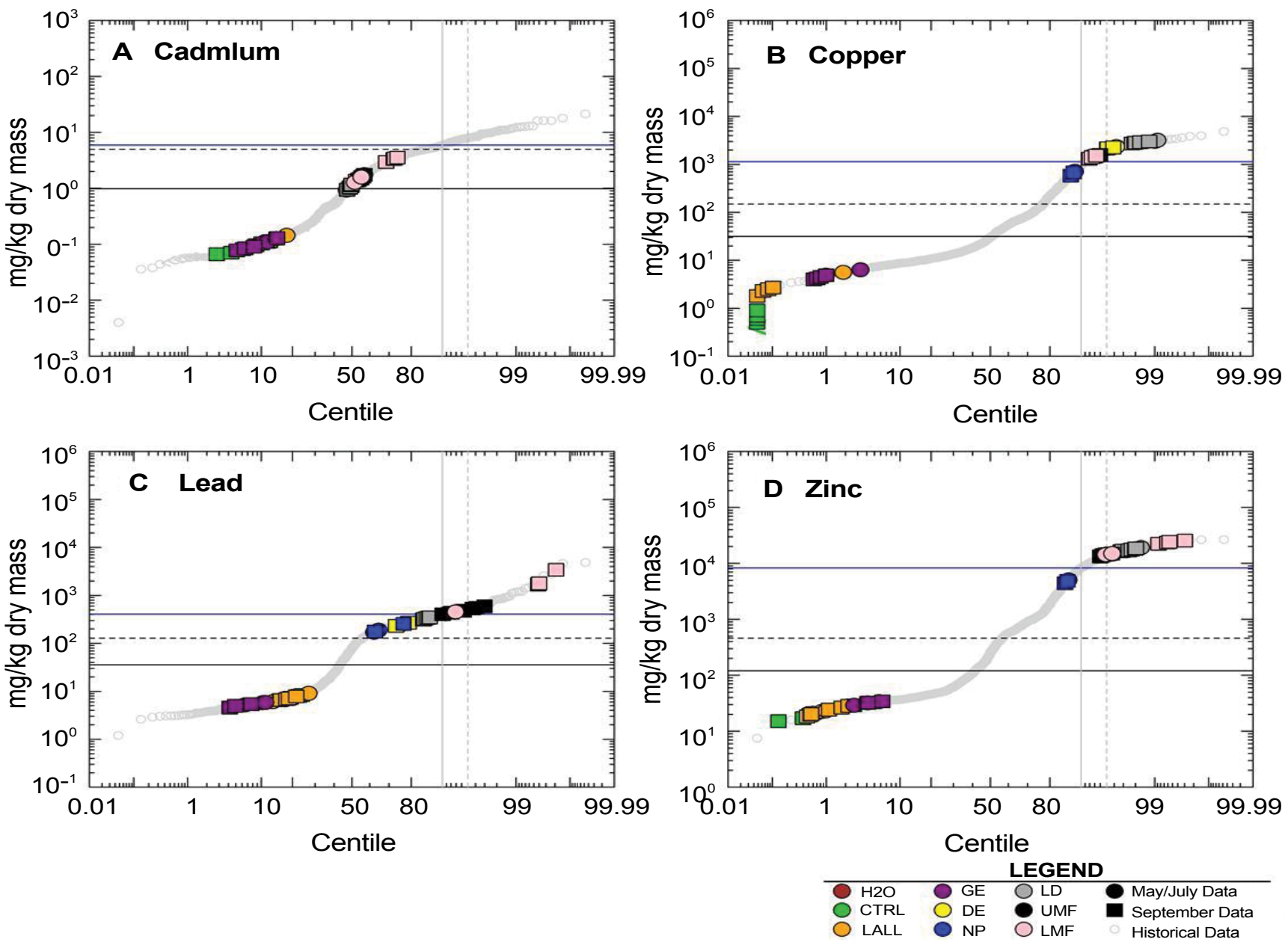

Figure 1: Total concentrations of acid-extractable metals of concern, cadmium (A), copper (B), lead (C), and zinc (D) in sediment samples evaluated within the white sturgeon sediment toxicity tests. The 90th centile of the distribution is designated with a solid horizontal blue line. A dashed line and a solid black line are used to identify the probably effect concentration and threshold effect concentration, respectively, as defined by MacDonald et al. [40] and are utilized and discussed in a parallel article to characterize risk [24]. Treatments included negative controls with water only $(\mathrm{H} 2 \mathrm{O})$ and artificial sediment (CTRL), reference sediments from Lower Arrow Lake (LALL) and Genelle (GE), and site sediments from Deadman's Eddy (DE), Northport (NP), Little Dallas (LD), Upper Marcus Flats (UMF) and Lower Marcus Flats (LMF).

All sampling devices used to extract samples from the sediment-water interface or from pore water were in agreement for concentrations of $\mathrm{Cu}$ (Figure 2). Concentrations of $\mathrm{Cu}$ measured in pore water at $1 \mathrm{~cm}$ below the sediment surface using peepers and DGT probes were significantly correlated $(\mathrm{p}<0.001)$ and not statistically different ( $p>0.05$; Supplemental Materials). Similarly, concentrations of $\mathrm{Cu}$ measured at the sediment-water interface were significantly correlated $(\mathrm{p}<0.05)$ among the three sampling techniques, including pipette suction, peeper, and DGT probes, and not statistically different ( $\mathrm{p}>0.05$ ) between peeper and DGT techniques, and DGT and suction techniques (Supplemental Materials), with measurements from DGT probes having the greatest variability. Differences between concentrations, achieved with any of the aforementioned sampling devices, appeared to be small and random, which suggests that any of these sampling methods could be used to characterize concentrations of $\mathrm{Cu}$ in pore water and water at the sediment-water interface.

Results of linear regression indicated that in all site sediment samples there was a significant positive relationship between concentrations of $\mathrm{Cu}$ in sediment to concentrations in pore water and overlying water.
This indicated that acid-extractable concentrations of $\mathrm{Cu}$ in sediment were a reasonable predictor of concentrations of $\mathrm{Cu}$ in pore water and could prove to be useful in assessing bioavailability and risk (DE $\mathrm{r}^{2}=$ $\left.0.85 ; \mathrm{NP}^{2}=0.82 ; \mathrm{LD} \mathrm{r}^{2}=0.92 ; \mathrm{UMF}^{2}=0.91 ; \mathrm{LMF}^{2}=0.77\right)$.

Zinc: Differences in median concentrations of $\mathrm{Zn}$ among all exposure chambers, regardless of sediment source, were relatively small (Figure 3). Estimated concentrations of $\mathrm{Zn}$ in overlying water in negative control $\left(\mathrm{H}_{2} \mathrm{O}\right.$ and $\left.\mathrm{CTRL}\right)$ and reference sediment (LALL and $\mathrm{GE})$ exposure chambers were $<6 \mu \mathrm{g} / \mathrm{L}$. Concentrations of $\mathrm{Zn}$ in overlying water measured in exposure chambers containing site sediments had slightly greater concentrations with estimates ranging between 6 and $15 \mu \mathrm{g} / \mathrm{L}$ and were considered statistically different $(\mathrm{p}<0.001)$ from GE reference sediment but not LALL reference sediment, with the exception of LMF and LALL comparison ( $\mathrm{p} \leq 0.001$; Supplemental Materials). Differences in concentrations of $\mathrm{Zn}$ at the sediment-water interface were lesser between negative controls, references, and site sediments. However, concentrations of $\mathrm{Zn}$ measured in water at the sediment-water interface with passive sampling devices in all site sediments were statistically greater $(p \leq 0.001)$ from LALL reference 

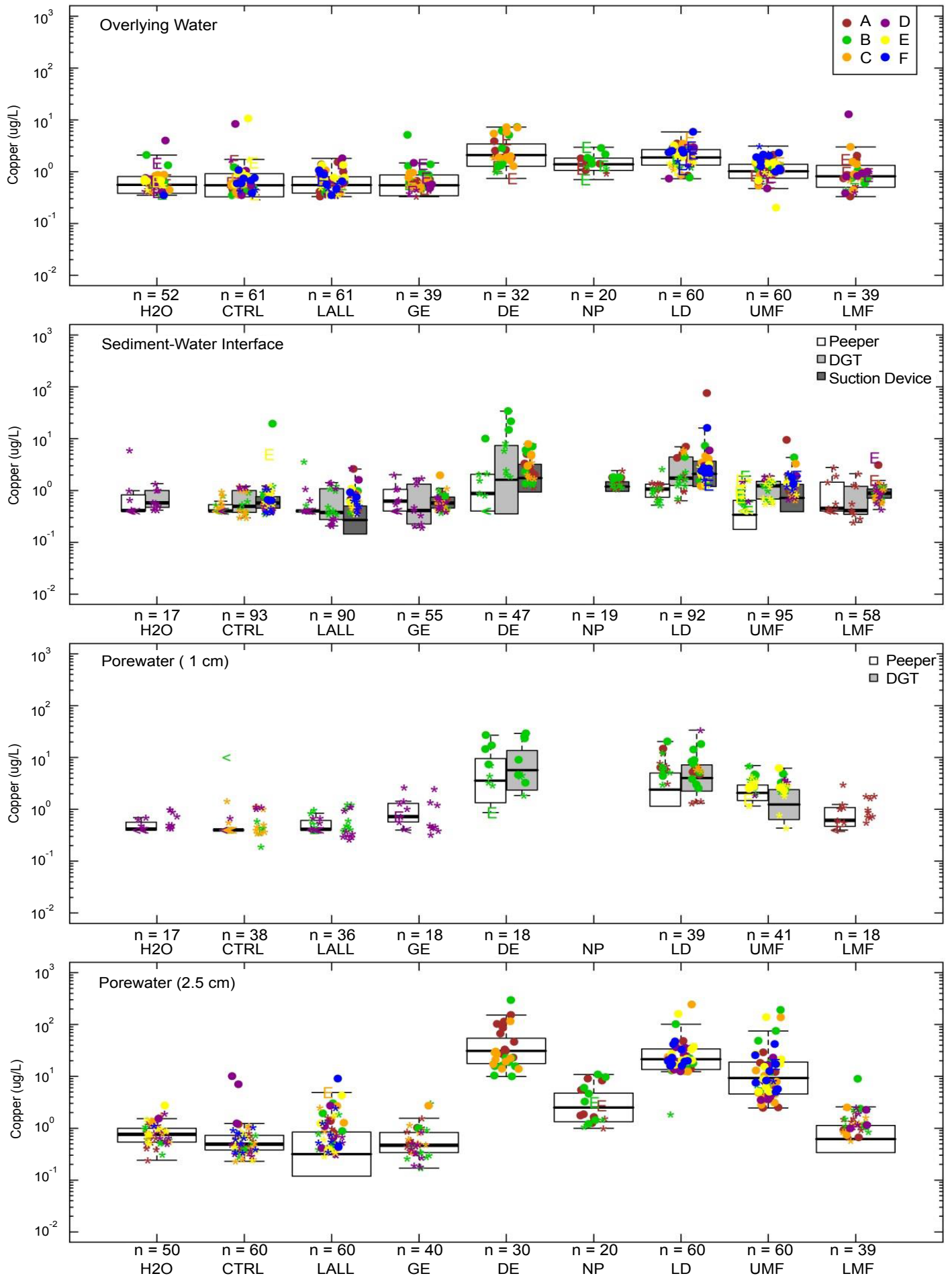

Figure 2: Concentrations of dissolved copper $(\mathrm{Cu})$ as a function of treatment and sample type. Samples types are presented in the following order: overlying water (top panel), sediment water interface water (2nd panel), pore water at $1 \mathrm{~cm}$ (3rd panel), and pore water at $2.5 \mathrm{~cm}$ (bottom panel). Where appropriate and applicable, concentrations as determined by use of different sampling techniques are identified within the top right-hand corner of respective panels. Individual measurements are shown as circles and color represents replicates, measurements below detection are illustrated with a less than symbol (“<") plotted at the detection limit, qualified samples due to blank contamination are illustrated with an asterisks $\left({ }^{*}\right)$, and date qualified as "estimated" are represented with the symbol "E" at the estimated value. The 25th and 75th centiles from the maximum likelihood estimate (MLE; see Supplemental Materials) calculated distribution is used for the edges of the box, the median is shown as a horizontal line drawn through the middle of the box. Whiskers show maximum and minimum values exclusive of extreme values. Extreme values were identified as values that were more than 1.5 times the inter-quartile range above the 75th or below the 25th centiles. Treatments included negative controls with water only (H2O) and artificial sediment (CTRL), reference sediments from Lower Arrow Lake (LALL) and Genelle (GE), and site sediments from Deadman's Eddy (DE), Northport (NP), Little Dallas (LD), Upper Marcus Flats (UMF) and Lower Marcus Flats (LMF). 
sediments. Median concentrations of $\mathrm{Zn}$ in pore water $($ at $1 \mathrm{~cm})$ from exposure chambers containing site sediments ranged between 3 and $<$ $70 \mu \mathrm{g} / \mathrm{L}$ (Figure 3), and concentrations varied within sites depending on sampling technique, with the greatest concentrations measured in DGT probes. Regardless, median concentrations of $\mathrm{Zn}$ in pore water (at $1 \mathrm{~cm}$ ) were slightly greater than those of the negative control and/ or reference pore water $($ at $1 \mathrm{~cm})$ concentrations $(3-15 \mu \mathrm{g} / \mathrm{L})$. All concentrations of $\mathrm{Zn}$ in pore water $($ at $1 \mathrm{~cm}$ ) in site sediments were statistically greater $(\mathrm{p} \leq 0.001)$ than concentrations of $\mathrm{Zn}$ in pore water $($ at $1 \mathrm{~cm}$ ) of one or more reference sediments (Supplemental Materials). Concentrations of $\mathrm{Zn}$ for pore waters collected at $2.5 \mathrm{~cm}$ fluctuated within sites and across all exposure chambers and ranged from 1 to $1000 \mu \mathrm{g} / \mathrm{L}$. However, values were largely qualified, primarily due to contamination in blanks (Figure 3 ), and results should be interpreted with caution. $\mathrm{Zn}$ is ubiquitous in the environment and in the laboratory and the exact sources of contamination in the present study are unknown

The different sampling methods used to quantify $\mathrm{Zn}$ in pore water or at the sediment-water interface often resulted in similar median measurements among techniques (Figure 3). Concentrations of $\mathrm{Zn}$ measured in pore water at $1 \mathrm{~cm}$ below the sediment surface using peepers and DGT probes were significantly correlated $(\mathrm{p}<0.001)$ and not statistically different ( $\mathrm{p}>0.05$; Supplemental Materials). At the sediment-water interface, only concentrations of $\mathrm{Zn}$ measured in peepers and DGT probes were significantly correlated ( $p \leq 0.05)$, but were not statistically similar $(\mathrm{p}<0.05)$ with a tendency for measurements from peepers to be slightly less than from DGTs and suction devices. Overall, the sampling methods used to characterize concentrations of $\mathrm{Zn}$ in pore water appear to be more interchangeable than methods used to characterize concentrations of $\mathrm{Zn}$ at the sediment-water interface.

Results of linear regression indicated that in all site sediments there was a significant positive relationship between concentrations of $\mathrm{Zn}$ in sediment to concentrations in pore water and overlying water. However, $r^{2}$ values were $\leq 0.50$ in all site sediments, indicating that concentrations of $\mathrm{Zn}$ in sediment are a poor predictor of concentrations of $\mathrm{Zn}$ in pore water $\left(\mathrm{DE} \mathrm{r}^{2}=0.49 ; \mathrm{NP} \mathrm{r}^{2}=0.33\right.$; $\mathrm{LD} \mathrm{r}^{2}=0.50$; $\mathrm{UMF}^{2}=$ 0.40 ; LMF r $^{2}=0.27$ ).

Cadmium: Median concentrations of $\mathrm{Cd}$ within all exposure chambers, including site sediments, for all sample types, including overlying water, sediment-water interface, and pore water, and all sampling techniques were generally $\leq 0.1 \mu \mathrm{g} / \mathrm{L}$ (Figure 4). Concentrations of $\mathrm{Cd}$ in Pore water at $2.5 \mathrm{~cm}$ depth in exposure chambers with site sediments were significantly greater $(p \leq 0.001)$ than exposure chambers with a reference sediment (Supplemental Materials). Specifically, median concentrations of Cd (0.2, 0.07, and $0.15 \mu \mathrm{g} / \mathrm{L}$ ) in exposure chambers with DE, NP, and UMF sediments, respectively, were significantly greater than those of the negative control and reference sediment exposure chambers (0.02 - $0.04 \mu \mathrm{g} \mathrm{Cd} / \mathrm{L}$ ). Based on measurements from active sampling devices, concentrations of $\mathrm{Cd}$ in overlying water, pore water, and at the sediment-water interface in exposure chambers with DE and UMF sediments were significantly greater than exposure chambers with reference sediment. In contrast, there were no statistical differences in concentrations of $\mathrm{Cd}$ between all site sediments and reference sediments in pore water or at the sediment-water interface based on peeper measurements.

Of the three sampling devices used to measure sediment-water interface samples, measurements with DGTs and suction devices demonstrated relatively good agreement for concentrations of $\mathrm{Cd}$ and were significantly correlated ( $\mathrm{p} \leq 0.05)$, although statistically different, while measurements made with peepers were consistently greater (Figure 4, Supplemental Material). Likewise, measurements in pore water made with peepers at $1 \mathrm{~cm}$ depth demonstrated poor correlation and were consistently greater for concentrations of $\mathrm{Cd}$ than measurements of pore water with DGTs at the same depth. Based on these results, DGTs, peepers, and suction devices do not appear to be interchangeable methods for measuring concentrations of $\mathrm{Cd}$.

Results of linear regression indicated that in all site sediment samples there was a significant positive relationship between concentrations of $\mathrm{Cd}$ in sediment to concentrations in pore water and overlying water. Only in certain site sediment samples, however, were concentrations of $\mathrm{Cd}$ in sediment moderate predictors of concentrations of $\mathrm{Cd}$ in pore water $\left(\mathrm{DE} \mathrm{r}^{2}=0.65 ; \mathrm{NP} \mathrm{r}^{2}=0.71 ; \mathrm{LD} \mathrm{r}^{2}=0.68 ; \mathrm{UMF} \mathrm{r}^{2}=0.63 ; \mathrm{LMF} \mathrm{r}^{2}\right.$ $=0.50)$.

Lead: Median concentrations of $\mathrm{Pb}$ within all exposure chambers, including site sediments, for all sample types, such as overlying water, sediment-water interface, and pore water, and all sampling techniques were generally $<1.0 \mu \mathrm{g} / \mathrm{L}$ (Figure 5). Differences in estimated median concentrations of $\mathrm{Pb}$ within the different matrices were relatively small between negative controls, reference sediments, and site sediments. However, concentrations of $\mathrm{Pb}$ in all site sediments were significantly greater $(\mathrm{p} \leq 0.001)$ in overlying water and at the sedimentwater interface than in reference sediment, based on measurements from active sampling techniques (Supplemental Materials). Also, concentrations of $\mathrm{Pb}$ in pore water measured in samples collected by active sampling (suction at $2.5 \mathrm{~cm}$ depth) in exposure chambers containing DE, UMF, and LMF sediments were significantly greater than those of reference sediments. In contrast, there were no significant differences in concentrations of $\mathrm{Pb}$ in pore water or at the sediment-water interface in $\mathrm{DE}, \mathrm{LD}$, or UMF sediments compared to reference sediments, based on passive sampling techniques. There were no significant correlations among concentrations of $\mathrm{Pb}$ among different sampling techniques utilized in pore water or sediment-water interface measurements. The different sampling techniques within individual exposure chambers measured different concentrations of $\mathrm{Pb}$ at the sediment-water interface, with a tendency towards elevated concentrations of $\mathrm{Pb}$ in samples from peepers in comparison to DGTs and suction devices. A similar tendency towards greater concentrations of $\mathrm{Pb}$ measured in pore water at $1 \mathrm{~cm}$ with peepers versus DGTs was also observed. Based on these results, DGTs, peepers, and suction devices do not appear to be interchangeable methods for measuring concentrations of $\mathrm{Pb}$. Results of linear regression indicated that in all site sediment samples there was a significant positive relationship between concentrations of $\mathrm{Pb}$ in sediment to concentrations in pore water and overlying water. Concentrations of $\mathrm{Pb}$ in sediment were moderate predictors of concentrations of $\mathrm{Pb}$ in pore water $\left(\mathrm{DE} \mathrm{r}^{2}=\right.$ $\left.0.65 ; \mathrm{NP}^{2}=0.71 ; \mathrm{LD} \mathrm{r}^{2}=0.58 ; \mathrm{UMF} \mathrm{r}^{2}=0.70 ; \mathrm{LMF}^{2}=0.64\right)$.

Other metals: There were no major differences in concentrations of the additional metals analyzed in pore water, overlying water, or at the sediment-water interface, between exposure chambers containing site sediments and reference sediments, except for antimony (Supplemental Materials). Estimated median concentrations of antimony in site sediment treatment groups were slightly elevated in overlying water and at the sediment-water interface, whereas concentrations in pore water differed significantly $(\mathrm{p} \leq 0.001)$ in exposure chambers containing site sediments $(0.1-100 \mu \mathrm{g} / \mathrm{L})$ compared to reference sediments $(<0.5$ $\mu \mathrm{g} / \mathrm{L})$. 

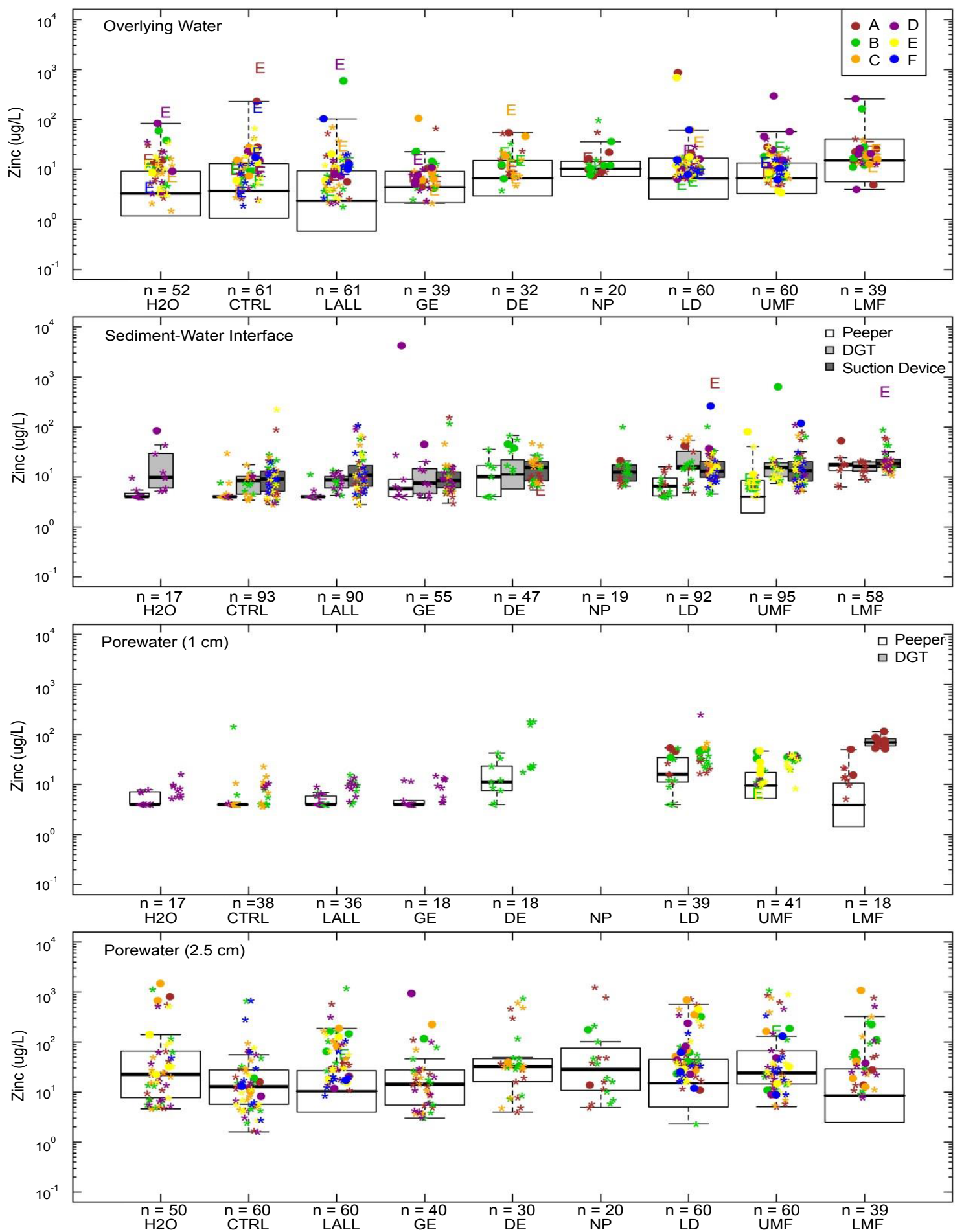

Figure 3: Concentrations of dissolved zinc $(\mathrm{Zn})$ as a function of treatment and sample type. Samples types are presented in the following order: overlying water (top panel), sediment water interface water (2nd panel), pore water at $1 \mathrm{~cm}$ (3rd panel), and pore water at $2.5 \mathrm{~cm}$ (bottom panel). Where appropriate and applicable, concentrations as determined by use of different sampling techniques are identified within the top right-hand corner of respective panels. Individual measurements are shown as circles and color represents replicates, measurements below detection are illustrated with a less than symbol (“<”) plotted at the detection limit, qualified samples due to blank contamination are illustrated with an asterisks (*), and date qualified as "estimated" are represented with the symbol "E" at the estimated value. The 25 th and 75 th centiles from the maximum likelihood estimate (MLE; see Supplemental Materials) calculated distribution is used for the edges of the box, the median is shown as a horizontal line drawn through the middle of the box. Whiskers show maximum and minimum values exclusive of extreme values. Extreme values were identified as values that were more than 1.5 times the inter-quartile range above the 75 th or below the 25 th centiles. Treatments included negative controls with water only (H2O) and artificial sediment (CTRL), reference sediments from Lower Arrow Lake (LALL) and Genelle (GE), and site sediments from Deadman's Eddy (DE), Northport (NP), Little Dallas (LD), Upper Marcus Flats (UMF) and Lower Marcus Flats (LMF). 

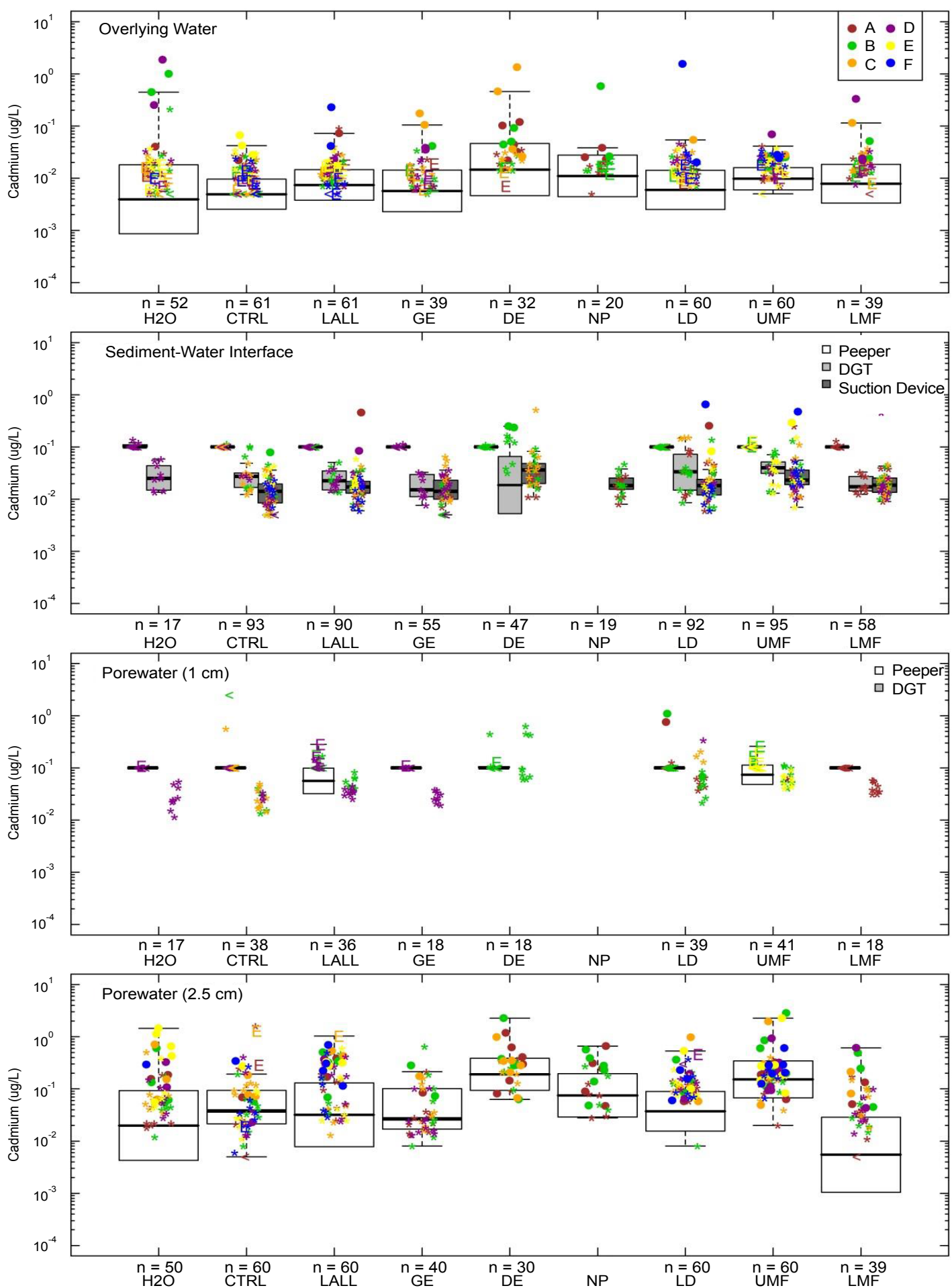

Figure 4: Concentrations of dissolved cadmium (Cd) as a function of treatment and sample type. Samples types are presented in the following order: overlying water (top panel), sediment water interface water (2nd panel), pore water at $1 \mathrm{~cm}$ (3rd panel), and pore water at $2.5 \mathrm{~cm}$ (bottom panel). Where appropriate and applicable, concentrations as determined by use of different sampling techniques are identified within the top right-hand corner of respective panels. Individual measurements are shown as circles and color represents replicates, measurements below detection are illustrated with a less than symbol (“<") plotted at the detection limit, qualified samples due to blank contamination are illustrated with an asterisks $\left({ }^{*}\right)$, and date qualified as "estimated" are represented with the symbol "E" at the estimated value. The 25th and 75th centiles from the maximum likelihood estimate (MLE; see Supplemental Materials) calculated distribution is used for the edges of the box, the median is shown as a horizontal line drawn through the middle of the box. Whiskers show maximum and minimum values exclusive of extreme values. Extreme values were identified as values that were more than 1.5 times the inter-quartile range above the 75 th or below the 25 th centiles. Treatments included negative controls with water only (H2O) and artificial sediment (CTRL), reference sediments from Lower Arrow Lake (LALL) and Genelle (GE), and site sediments from Deadman's Eddy (DE), Northport (NP), Little Dallas (LD), Upper Marcus Flats (UMF) and Lower Marcus Flats (LMF). 

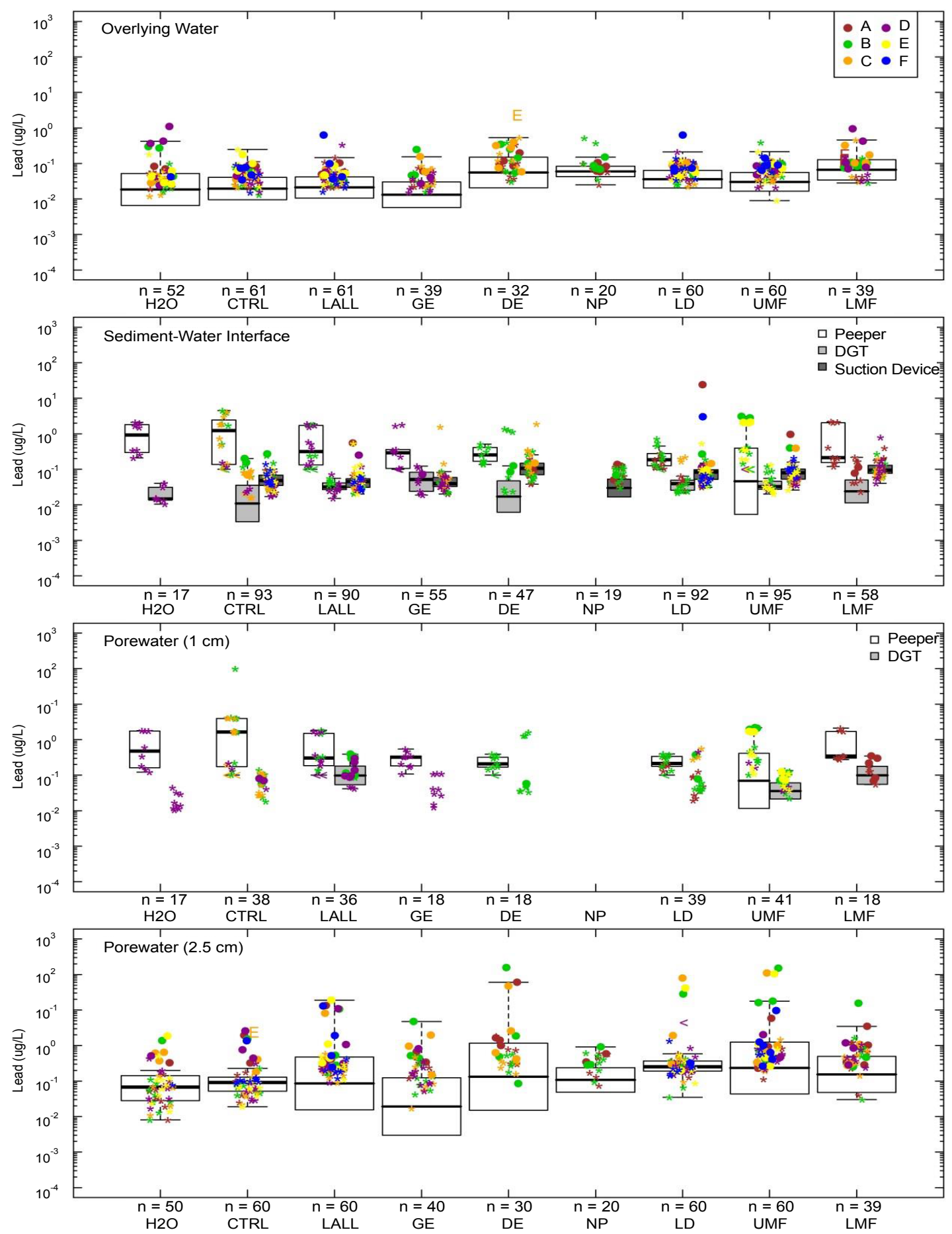

Figure 5: Concentrations of dissolved lead $(\mathrm{Pb})$ as a function of treatment and sample type. Samples types are presented in the following order: overlying water (top panel), sediment water interface water (2nd panel), pore water at $1 \mathrm{~cm}$ (3rd panel), and pore water at $2.5 \mathrm{~cm}$ (bottom panel). Where appropriate and applicable, concentrations as determined by use of different sampling techniques are identified within the top right-hand corner of respective panels. Individual measurements are shown as circles and color represents replicates, measurements below detection are illustrated with a less than symbol (" $<$ ") plotted at the detection limit, qualified samples due to blank contamination are illustrated with an asterisks $\left({ }^{*}\right)$, and date qualified as "estimated" are represented with the symbol "E" at the estimated value. The 25th and 75th centiles from the maximum likelihood estimate (MLE; see Supplemental Materials) calculated distribution is used for the edges of the box, the median is shown as a horizontal line drawn through the middle of the box. Whiskers show maximum and minimum values exclusive of extreme values. Extreme values were identified as values that were more than 1.5 times the inter-quartile range above the 75 th or below the 25 th centiles. Treatments included negative controls with water only (H2O) and artificial sediment (CTRL), reference sediments from Lower Arrow Lake (LALL) and Genelle (GE), and site sediments from Deadman's Eddy (DE), Northport (NP), Little Dallas (LD), Upper Marcus Flats (UMF) and Lower Marcus Flats (LMF). 


\section{Comparisons of sampling techniques}

There were differences in measured concentrations of metal among sampling techniques within a matrix for most of the metals analyzed. Considering all the TAL metals, concentrations of metals from DGTs and suction devices tended to be similar at the sediment-water interface whereas measurements from peepers were often greater in comparison. Similarly, in pore water at $1 \mathrm{~cm}$ depth, concentrations of metals in water in peepers were often greater than those estimated by DGTs. This trend could, in part, be due to the fact that concentrations in peepers represent metals averaged over time, once equilibrium has been established with the surrounding matrix, whereas suction devices measure point source concentrations of metals. Alternatively, assuming that the metal that is removed from a matrix is rapidly resupplied from the solid phase in sediment, DGTs characterize fluxes of metals and provide a measurement of average concentrations of metals during deployment time within a matrix [37]. Previous studies have investigated issues with re-supply and have found that in cases where it is insufficient, DGT measurements can result in calculated concentrations of metals that are significantly less than concentrations of metals measured in pore water using other, more traditional techniques, such as core sampling and centrifugation of sediments [38-40]. For certain metals in the present study, however, such as $\mathrm{Cu}$, $\mathrm{Zn}$, and $\mathrm{Al}$, concentrations of metals in water at the sediment-water interface and pore water at $1 \mathrm{~cm}$ depth were relatively similar between these two methods of sampling.

Use of air stones for extraction of pore water has several advantages over peepers and DGTs, including the ability to extract relatively large sample volumes that in turn allow for a greater suite of chemical analyses. In addition, air stones can be used for more than one sampling event without having to disturb the sediment. Peepers and DGTs, however, can sample more than one matrix at a time and can be used in the laboratory or in the field.

\section{Conclusions}

Sediments investigated during the present study covered a range of concentrations of targeted metals that were representative and consistent of the extent of concentrations observed with UCR site sediments, and captured the upper concentration range of previously reported data. In the present study, acid-extractable concentrations of $\mathrm{Cu}, \mathrm{Cd}, \mathrm{Zn}$, and $\mathrm{Pb}$ in whole samples of site sediments were significantly greater than those in reference sediments. Of the four primary metals of concern, $\mathrm{Cu}, \mathrm{Cd}, \mathrm{Pb}$, and $\mathrm{Zn}$, concentrations of $\mathrm{Cu}$, primarily in pore water, were greatest in exposure chambers containing site sediments compared to those in reference sediments. Concentrations of $\mathrm{Cu}$ and $\mathrm{Zn}$ were significantly greater in matrices of site sediments compared to reference sediments more often than $\mathrm{Cd}$ and $\mathrm{Pb}$. Active and passive sampling techniques resulted in similar estimates of concentrations of $\mathrm{Cu}$ in pore water and at the sediment-water interface, and comparable measurements for concentrations of $\mathrm{Zn}$. In contrast, sampling techniques resulted in dissimilar measurements for concentrations of $\mathrm{Pb}$ and $\mathrm{Cd}$, with a tendency towards greater concentrations in peepers compared to DGTs in both pore water and at the sediment-water interface. Discrepancies in measurements of concentrations of metals between peepers and DGTs were a common trend for a number of the non-target metals analyzed in the present study. At the sediment-water interface, however, DGTs and active sampling through suction often resulted in relatively similar measurements for many of the metals.

Bioavailability of metals is a key factor to assessing risk of exposure to metals associated with sediment. In general, concentrations of dissolved metals in pore water are considered to be the most representative of the fraction of metal bioavailable to sediment-dwelling organisms. With contaminated sediments, there is a concern that metals might leach out of sediments into pore water at concentrations sufficient to have adverse effects on organisms associated with the sediments. When considering effects of metals associated with sediments on benthic dwelling fish such as sturgeon, matrices other than pore water might be a more applicable route of exposure. Therefore, the present study characterized concentrations of metals in various matrices associated with sediment. Concentrations of metals in sediment often resulted in significant concentrations of metals in pore water and overlying water; although results varied depending on the sampling technique employed. When active sampling through suction was considered, linear regression was a relatively effective means of characterizing the movement of metal in sediment to pore water and overlying water for certain metals such as $\mathrm{Cu}$. However, the present study demonstrated that measured concentrations of dissolved metal in matrices associated with sediment can differ depending on the choice of sampling method, matrix, and analyte. Differences in estimated concentrations of metals among the methods applied highlights the difficulty in assessing the true risk of exposure to metals associated with sediments. To minimize uncertainty, concentrations of metals could be measured in bodies of organisms, but this is difficult under field conditions.

Regardless of these differences among methods of sampling, concentrations of $\mathrm{Cu}, \mathrm{Cd}, \mathrm{Pb}$, and $\mathrm{Zn}$ calculated from any of the techniques employed to sample water at the sediment-water interface or in overlying water in the present study were less than the EPA national criteria of $6.0 \mu \mathrm{g} / \mathrm{L}, 0.174 \mu \mathrm{g} / \mathrm{L}, 1.46 \mu \mathrm{g} / \mathrm{L}$, and $78 \mu \mathrm{g} / \mathrm{L}$, respectively, and criteria for the state of Washington for the protection of aquatic life of $7.4 \mu \mathrm{g} / \mathrm{L}, 1.51 \mu \mathrm{g} / \mathrm{L}, 1.46 \mu \mathrm{g} / \mathrm{L}$, and $69 \mu \mathrm{g} / \mathrm{L}$, respectively. These criteria do not take into account the bioavailable fraction of metals, except for EPA criteria for $\mathrm{Cu}$ that utilizes the Biotic Ligand Model. Therefore, when considering pore water, interpretations are more difficult since water quality characteristics, such as hardness and DOC, were more variable among sediments and affect site-specific water quality standards. In addition, questions as to whether or not benthic fish such sturgeon are exposed to metals associated with pore water become important. A more appropriate comparison would be concentrations corrected for chemical activity, and binding to inorganic and organic ligands by use of the Biotic Ligand Model. The analytical data reported herein are utilized in a parallel article to characterize risk, and in turn, compare predictions to the biological results from exposure of early life stage white sturgeon to metals in sediments of the Upper Columbia River [24].

\section{Acknowledgements}

This work was approved by the University of Saskatchewan's Animal Research Ethics Board, and adhered to the Canadian Council on Animal Care guidelines for humane animal use. The Aquatic Toxicology Research Facility and Toxicology Graduate program at the University of Saskatchewan was instrumental in conducting this research. This research was funded by an unrestricted grant from Teck American to J.P. Giesy and M. Hecker. The authors would like to thank S. Beitel, B. Tendler, and the U.S. EPA. A special thanks to R. Ek and the team at the Kootenay Trout Hatchery for facilitating this research. The research was supported in part by a Discovery Grant from the National Science and Engineering Research Council of Canada, and a grant from the Western Economic Diversification Canada. Profs. Hecker and Giesy were supported by the Canada Research Chair program

\section{References}

1. Birstein VJ (1993) Sturgeons and paddlefishes: Threatened fishes in need of conservation. Conserv Biol 7: 773-787.

2. Gisbert E, Williot $P(2002)$ Advances in the larval rearing of Siberian sturgeon J Fish Biol 60: 1071-1092. 
Citation: Vardy DW, Doering JA, Santore R, Ryan A, Giesy JP et al. (2015) Assessment of Columbia River Sediment Toxicity to White Sturgeon: Concentrations of Metals in Sediment, Pore water and Overlying Water. J Environ Anal Toxicol 5: 263. doi:10.4172/2161-0525.1000263

3. $\mathrm{Hu} J$, Zhang $Z$, Wei $\mathrm{Q}$, Zhen $\mathrm{H}$, Zhao $\mathrm{Y}$ et al. (2009) Malformations of the endangered Chinese sturgeon, Acipenser sinensis, and its causal agent. Proc Nat Acad Sci 106: 9339-9344.

4. Irvine RL, Schmidt DC, Hildebrand LR (2007) Population Status of White Sturgeon in the Lower Columbia River within Canada. Am Fish Soc 136: 1472 1479 .

5. Luk'yanenko VI, Vasil'ev AS, Luk'yanenko VV, Khabarov MV (1999) On the increasing threat of extermination of the unique Caspian sturgeon populations and the urgent measures required to save them. J Appl Ichthyol 15: 99-102.

6. Paragamian VL, Hansen MJ (2008) Evaluation of recovery goals for endangered white sturgeon in the Kootenai River, Idaho. N Am J Fish Manage 28: 463-470.

7. Hildebrand L, McLeod C, McKenzie S (1999). Status and management of white sturgeon in the Columbia River in British Columbia, Canada: an overview. J Appl Ichthyol 15: 164-172.

8. Hildebrand LR, Parsley M (2013) Upper Columbia White Sturgeon Recovery Plan - 2012 Revision. Prepared for the Upper Columbia White Sturgeon Recovery Initiative.

9. Besser JM, Brumbaugh WG, Ivey CD, Ingersoll CG, Moran PW (2008). Biological and chemical characterization of metal bioavailability in sediments from Lake Roosevelt, Columbia River, Washington, USA. Arch Environ Contam Toxicol 54: 557-570.

10. Bortleson GC, Cox SE, Munn MD, Schumaker RJ, Block EK (2001) Sedimentquality assessment of Franklin D Roosevelt Lake and the upstream reach of the Columbia River, Washington, 1992. USGS Water Supply Paper 2496.

11. U.S. Environmental Protection Agency (2006 a) Phase 1 sediment sampling data evaluation-UCR CERCLA RI/FS. Contract No 68-S7-04-01. USEPA Seattle, WA.

12. U.S. Environmental Protection Agency (2006 b) UCR Site CERCLA RI/FS summary and evaluation of 2005 sediment toxicity test results. Technical memorandum. USEPA, Seattle, WA.

13. Salomons W, De Rooij NM, Kerdijk H, Bril J (1987) Sediments as sources of contaminants. Hydrobiol 149:13-30.

14. Sullivan $P$, Taylor KG (2003) Sediment and pore water geochemistry in a metal contaminated estuary, Dulas Bay, Anglesey. Environ Geochem Health 25: 115 133.

15. Ankley GT, Di Toro DM, Hansen D, Berry WJ (1996) Technical basis and proposal for deriving sediment quality criteria for metals. Environ Toxicol Chem 15:2056-2066

16. Fairbrother A, Wenstel R, Sappington K, Wood W (2007) Framework for metals risk assessment. Ecotoxicol Environ Saf 68: 145-227.

17. Paulson AJ, Wagner RJ, Sanzolone RF, Cox SE (2006) Concentrations of elements in sediments and selective fractions of sediments, and in natural waters in contact with sediments from Lake Roosevelt, Washington, September 2004. U.S. Geological Survey Open-File Report 2006-1350, 84.

18. Paulson AJ, Cox SE (2007) Release of elements to natural water from sediments of Lake Roosevelt, Washington, USA. Environ Toxicol Chem 26: 2550-2559.

19. Doig L, Liber K (2009) Dialysis mini-peeper for measuring pore-water meta concentrations in laboratory sediment toxicity and bioavailability tests. Environ Toxicol Chem 19: 2882-2889.

20. Davlson W, Zhang H (1994) In situ speciation measurements of trace components in natural waters using thin-film gels. Nature 367: 546-548.

21. Mudroch A, Azcue JM, Mudroch $P$ (1997) Manual of Physico- Chemical Analysis of Aquatic Sediments. Lewis Publishers, Boca Raton, FL, USA.

22. Robertson EL, Liber K (2009) Effect of sampling method on contaminan measurement in pore-water and surface water at two uranium operations: can method affect conclusions. Environ Monit Assess 155: 539-553.

23. U.S. Environmental Protection Agency (2006c) Guidance on systematic planning using the data quality objectives process. EPA-240-B-06-001. Office of environmental information, Washington, DC.

24. Vardy DW, Santore R, Ryan A, Giesy JP, Hecker M (2015) Toxicity assessment of metals associated with sediment in the Columbia River to early life stages of white sturgeon. J Environ Anal Toxicol 5:2.
25. Howell MD, McLellan JG (2006) Lake Roosevelt white sturgeon recovery project, annual report January 2004 - March 2005. Bonneville Power Administration, Project No. 1995-027-00. Portland, OR.

26. Weakland RJ, Fosness RL, Williams ML, Barton GJ (2011) Bathymetric and sediment facies maps for China Bend and Marcus Flats, Franklin D. Roosevelt Lake, Washington, 2008 and 2009. USGS Scientific Investigations Map 3150.

27. ASTM (2009) Standard guide for conducting early life-stage toxicity tests with fishes. E 1241-05 American Society for Testing and Materials, West Conshohocken, PA, USA.

28. Zhang $\mathrm{H}$ (2003) Practical guide to assembling and using DGT sediment probes DGT Research Ltd., Skelmorlie, Quernmore, Lancaster, UK.

29. U.S. Environmental Protection Agency (1992) Guidance for data usability in risk assessment (Part A). EPA Publication 9285.7-09A Office of emergency and remedial response, Washington, DC.

30. U.S. Environmental Protection Agency (1999) US EPA Contract Laboratory Program national functional guidelines for organic data review. EPA540-R-99-008 Office of emergency and remedial response, Washington, DC

31. U.S. Environmental Protection Agency (2004) US EPA Contract Laboratory Program national functional guidelines for inorganic data Review. EPA540-R-04-004 Office of emergency and remedial response, Washington, DC.

32. U.S. Environmental Protection Agency (2009) Guidance for labeling externally validated laboratory analytical data for Superfund use. EPA-540-R08-008 Office of environmental information, Washington, DC.

33. Helsel DR (1990) Less than obvious: statistical treatment of data below the detection limit. Env Sci Technol 24:1766-1774.

34. Dean CB, Nielsen JD (2007) Generalized linear mixed models: a review and some extensions. Lifetime Data Anal 13: 497-512.

35. Zhang H, Davison W, Miller S, Tych W (1995) a. In situ high resolution measurements of fluxes of $\mathrm{Ni}, \mathrm{Cu}, \mathrm{Fe}$, and $\mathrm{Mn}$ and concentrations of $\mathrm{Zn}$ and Cd in pore waters by DGT. Geochimica et Cosmochimica Acta 59: 4181-4192.

36. Zhang H, Davison W (1999) Diffusional Characteristics of hydrogels used in DGT and DET techniques. Analytica Chimica Acta, 398: 329-340.

37. Zhang H, Davison W (2001) In situ speciation measurements. Using diffusive gradients in thin films (DGT) to determine inorganically and organically complexed metals. Pure Appl Chem 73: 9-15.

38. Zhang H, Davison W (1995) Performance characteristics of diffusion gradients in thin films for the in situ measurement of trace metals in aqueous solution. Analytical Chemistry 67: 3391-3400.

39. Fones GR, Davison W, Holby O, Jorgensen BB, Thamdrup B (2001) Highresolution metal gradients measured by in situ DGT/DET deployment in Black Sea sediments using an autonomous benthic lander. Limnol Oceanogr 46: 982 988.

40. MacDonald DD, Ingersoll CG, Berger TA (2000) Development and evaluation of consensus-based sediment quality guidelines for freshwater ecosystems. Arch Environ Contam Toxicol 39:20-31. 